\title{
LA CONSTRUCCIÓN ARGUMENTATIVA DE LA REVISTA ARGENTINA EXPRESO IMAGINARIO SOBRE LOS PROBLEMAS AMBIENTALES DE LA DÉCADA DEL SETENTA
}

\section{The Argumentative Construction of Environmental Issues in the 70s in Argentine Magazine Expreso Imaginario}

\section{A construção argumentativa da revista argentina Expreso Imaginario sobre os problemas ambientais da década de 1970}

Ayelen Dichdji, Universidad Nacional de Quilmes / CONICET / CEAR-UNQ (Argentina) adichdji@yahoo.com.ar

\section{Recibido: 15 de marzo de 2016 \\ Aceptado: 11 de julio de 2016}

\section{RESUMEN}

Este trabajo estudia, a través del análisis de los topoi, la construcción argumentativa sobre la cuestión ambiental en la revista argentina contracultural Expreso Imaginario (1976-1983). Esto permite reflexionar sobre el lugar que ocupa la temática ambiental dentro de la publicación para la época: ¿es un tema relevante por tratarse de un acontecimiento que quiebra con la cotidianidad y se torna noticioso? ¿O, en realidad, se trata de un proceso que es clave y propio del clima de época? ¿Hasta qué punto la noticia se vuelve espectáculo y la crisis ambiental un 
producto redituable para los medios? Para contestar estos interrogantes se trabaja con una perspectiva pluridisciplinar que vincula la comunicación, la historia ambiental y el análisis crítico del discurso.

Palabras clave: medios de comunicación, crisis ambiental, análisis crítico del discurso, historia ambiental.

\begin{abstract}
In this paper we studied the argumentative construction of environmental issues in Argentine magazine Expreso Imaginario (1976-1983). This analysis allows us to think about some topics, such as: is the environmental crisis a significant issue because it becomes newsworthy? Or is it a key process of that time? When does the news become a show and the environmental issues turn into a media product? To answer this questions we've used a multidisciplinary perspective that links Communication, Environmental history and Critical discourse analysis.
\end{abstract}

Keywords: Media, environmental history, environmental issues, critical discourse analysis.

\title{
RESUMO
}

Este trabalho estuda através da análise dos topoi, a construção argumentativa sobre a questão ambiental na revista argentina contratual Expreso Imaginario (1976-1983). Isto permite refletir sobre o lugar que ocupa a temática ambiental dentro da publicação para a época: é um tema relevante por tratar-se de um acontecimento que rompe com a cotidianidade e torna-se noticioso? Ou na realidade, trata-se de um processo que é chave e próprio do clima da época? Até que ponto a notícia vira-se espetáculo e a crise ambiental um produto rentável para os meios? Para responder estes interrogantes se trabalha com uma perspectiva multidisciplinar que vincula a Comunicação, a História Ambiental e a Análise Crítica do Discurso.

Palavras-chave: meios de comunicação, crise ambiental, análise crítica do discurso, história ambiental.

\section{Introducción}

En las últimas décadas, la preocupación por la cuestión ambiental y la emergencia de los problemas socioambientales suscitaron un progresivo interés en la relación hombre-medio que habilitó nuevos marcos de interpretación dado que la alteración del ambiente habla de la propia sociedad que la genera. Al mismo tiempo es inobjetable 
que ese vínculo entre la sociedad y el ambiente es definido por los procesos políticos, sociales y económicos que protagonizan los hombres en su apropiación de los espacios y en la utilización de sus recursos (Zarrilli, 2014).

Dado su abordaje pluridisciplinar la historia ambiental impulsa la relectura de los desequilibrios ambientales en clave histórica, atendiendo a las relaciones sociedad-medio. Además, aborda las percepciones de la naturaleza y la influencia de esta en la vida social, las formas de intervención de bajo impacto, los procesos de urbanización, la transformación del paisaje, entre otros aspectos. Al decir de Palacio, este tipo de historia se diferencia de otras porque considera las particularidades tanto relevantes como dinámicas de la naturaleza "reintroduciéndola en la historia humana" (Palacio, 2003, p.1). Así mismo, atiende a las relaciones sociedad-ambiente y establece diálogos con otros campos disciplinares, como el análisis crítico del discurso.

Estas disputas entre sociedad-naturaleza también se proyectan en el universo discursivo y conforman un orden social de los discursos (Foucault, 1973) donde tanto la producción y la circulación como la intervención y la regulación de estos: construyen identidades, relaciones sociales y sistemas de conocimiento de los hablantes (Martín Rojo, 1997; Fairclough, 1995).

En este contexto, los medios de comunicación se posicionan como vehículos de información sobre temáticas diversas entre las cuales podemos destacarlas cuestiones ambientales devenidas en catástrofes y riesgos ambientales. Así, el discurso mediático construye una representación del mundo de acuerdo a la jerarquización ${ }^{1}$ sobre qué se muestra y qué se omite, qué temas son relevantes y quiénes serán las voces autorizadas para hablar al respecto. Por esta razón, se colocan como protagonistas centrales que desempeñan un rol significativo al momento de configurar las opiniones, tanto públicas como políticas, sobre el acontecer social.

En el presente trabajo nos proponemos analizar la estructura argumentativa de la revista argentina Expreso Imaginario² durante sus tres primeros años de aparición (1976-1978). De modo particular, nos interesa estudiar la mención que se realiza sobre la problemática ambiental. Específicamente intentaremos responder al interrogante sobre ¿qué argumentos construye la publicación para abordar la cuestión ambiental y cómo los presenta? Cabe destacar que este medio fue partícipe de movimientos influenciados por tendencias vanguardistas, con un fuerte hincapié en las preocupaciones por cuestiones socioculturales. Esta publicación, dentro de la prensa gráfica contracultural argentina, fue pionera por ofrecer un lugar destacado a temas inéditos para la época y no abordados por otros medios de comunicación como la crisis ambiental mundial que identifica como un eje de discusión. En tanto fuente de información histórica sobre prácticas socioambientales, y sus repercusiones en el pasado reciente, nos permite cuestionar de qué manera desde los medios gráficos contraculturales se comenzó a presentar la crisis

1 Debido a que el mundo es inabarcable e inconmensurable para las personas, la realidad se torna abstracta ya que no puede experimentarse en forma directa. Al decir de Gotthard Bechmann "aprendemos principalmente sobre los peligros a través de los medios de comunicación y debemos confiar en determinados informes. Estos, a su vez, se basan en la ciencia y en sus métodos. Nos preocupamos por los riesgos comunicados, que podamos creer o no, ya que no podemos verificarlos por nosotros mismos" (Bechmann, 2004, p.21).

2 La revista Expreso Imaginario se publica por primera vez en agosto de 1976 y deja de editarse en 1983. No obstante, la temática ambiental solo mantiene vigencia hasta 1981, dado que con la partida de sus fundadores los nuevos directores deciden abocarse únicamente a los contenidos sobre música rock. 
ambiental en la década del setentay cómo esta problemática dialoga con los pilares propuestos por la historia ambiental.

\section{Una mirada transdisciplinar sobre la problemática ambiental}

El panorama de crisis política e inestabilidad de la economía capitalista mundial, a mediados de la década del sesenta y principios de los setenta,se traduce al problema ambiental puesto que estees una cuestión política y de vínculos de poder.En ello se debe enfatizar "si se quiere avanzar en soluciones compartidas, justas y aceptadas por toda la comunidad internacional o por lo menos por su gran mayoría” (Estonssoro Saavedra, 2009, p. 3).

Nos enfrentamos a una problemática compleja y de múltiples causas, por lo tanto, para su abordaje se requieren diversas perspectivas de análisis. Es por esta razón que, en este artículo,proponemos un estudio pluridisciplinar que conjugue tanto la historia ambiental como las herramientas propuestas por el análisis crítico del discurso para aproximarnos al tratamiento mediático que sobre esta cuestión realiza la revista Expreso Imaginario en la década del setenta en Argentina.

\section{La perspectiva histórica de la problemática ambiental}

El interés por el cuidado y la preservación, tanto del medio ambiente como de los recursos naturales, surgen en la década del sesenta a raíz de la crisis ambiental. En la carrera por consolidar sus impulsos científicos y tecnológicos de avance y modernización - como consecuencia de la creciente capacidad de destrucción que tiene la sociedad-el deterioro de la naturaleza resulta inevitable.

Esta tendencia siguió con atención las preocupaciones tanto de grupos ambientalistas como, progresivamente, del mundo académico. Desde la década del sesenta-y con mayor ímpetu a partir los Informes del Club de Roma de 1972, 1974, 1976 y la Cumbre de Estocolmo de 1972- se habilitó la intervención de nuevos y variados movimientos sociales. Estos contribuyeron a modificar la concepción predominante de una "naturaleza ilimitada", por una "noción que enfatizaba tanto la diversidad como la fragilidad de un mundo natural considerado muy valioso" (Leal, Pádua y Soluri, 2013, p.6). Esto implica el incremento de la conciencia social sobre la trascendencia de esta temática. De esta forma, se considera que estos nuevos actores fueron pioneros en denunciar, en primer lugar, el alcance de las relaciones entre sociedad-ambiente $y$, en segundo lugar, la magnitud de los conflictos ambientales que azotan dicho vínculo y lo ponen en jaque.

No obstante, la confirmación de que el mundo afronta un profundo inconveniente bautizado "crisisambiental" se presentó en Estocolmo en 1972 en la primera conferencia sobre Medio Ambiente Humano realizada por la Organización de las Naciones Unidas (ONU). Allí se establecía que:

La capacidad del hombre de transformar lo que le rodea, utilizada con discernimiento, puede llevar a todos los pueblos los beneficios de desarrollo [aunque] aplicado de forma imprudente [...] puede causar daños incalculables al ser humano y a su medio. [Ello implica] niveles peligrosos de contaminación del agua, el aire, la tierra, y los seres vivos [así como] grandes trastornos del equilibrio ecológico de la biósfera; destrucción y agotamiento de recursos insustituibles y graves deficiencias [en] salud física, mental y social del hombre (Estonssoro Saavedra, 2009, p. 4). 
Estos ejes los veremos ejemplificados más adelante cuando nos adentremos en el análisis de nuestra fuente. Por otra parte, el estudio de los vínculos entre ambiente y sociedad conlleva el examen de "los efectos sociales de las alteraciones del entorno natural y las repercusiones que sobre este tienen las transformaciones y los cambios sociales" (García, 2011, p.15). De este modo, las cuestiones relacionadas al ambiente dejan de ser solo una preocupación de sectores minoritarios - ambientalistas, por ejemplo- para transformarse en un tema de relevancia social generalizada.

La relación sociedad-ambientees compleja de abordar, ya que "una civilización que cree que la naturaleza le pertenece para dominarla y que dispone de una tecnología poderosa tiene la misma probabilidad de sobrevivir que una bola de nieve a mitad del infierno" (García, 2011, p. 293). En otras palabras, siguiendo a Worster ([1984] 2000), el aceleramiento del deterioro ambiental en el planeta se debe, en parte y desde la Segunda Guerra Mundial, al resultado de los emprendimientos científicos impulsados por las motivaciones de la humanidad. En síntesis, para el autor la ciencia ha hecho posible la moderna devastación de la naturaleza.

En este sentido, se requiere un enfoque que complemente tanto las ciencias naturales como las sociales, permita un abordaje holístico de la problemática y proponga posibles lecturas para resolver estas cuestiones. Dado que, "en la medida en que se incrementa la incertidumbre [...] los atributos de la ciencia tradicional, su certeza y su neutralidad valorativa resultan más cuestionables" (García, 2011, p. 293).

En este contexto de progresivo interés por parte de los académicos en abordar y complejizar las relaciones naturaleza-sociedad, cobra sentido la emergencia de la historia ambiental ${ }^{3}$. Este campo se ubicó como encargado de aproximarse al origen y evolución de los fenómenos ambientales que emergen en el mundo. Así mismo, conjuga las perspectivas de distintas disciplinas y, al decir de Palacio, "describe y certifica los rasgos y aventuras de la interacción humana con el resto de la naturaleza” (Palacio, 2003, p. 2). De estaforma, revisitar e integrar a nuestros estudios la dimensión ambiental beneficia la comprensión sobre el pasado reciente y supone una contribución al discernimiento de las dificultades del presente. De acuerdo con esto, la relación sociedad-medio se entiende como un proceso de larga duración, por este motivo la transformación de la naturaleza, como menciona Leal (2002), ha sido un tema predominante en la historia ambiental.

Por su parte, la temática ambiental excede las inquietudes del ámbito académico, teniendo en cuenta que se apropia de un espacio en los debates políticos, económicos y culturales. Esto se debe a una progresiva toma de conciencia que implica valorar el ambiente como una dimensión irreductible en la estructura socioeconómica de las sociedades. En paralelo, se proyecta como un espacio cuyo deterioro atenta contra la calidad de vida de los seres humanos y, finalmente, donde su desgaste simboliza el deterioro estructural de la sociedad occidental contemporánea.

3 Para complementar la información sobre los enfoques propuestos por la Historia Ambiental y sus diferentes vertientes que, por cuestiones de espacio, no podemos incluir en este artículo consideramos necesario revisar los trabajos de Castro Herrera (2004), Soluri (2013), Sedrez (2002), Leal (2002), Padua (2002), Zarrilli (2004; 2011; 2012; 2014), Cronon (1972), Worster (1984), Palacio (2002; 2003), Gallini (2002; 2005; 2009), McNeill (2005), Nash (1974), O 'Connor (2001), Giglo (1981), Martínez Alier (1993), González de Molina (1988; 1993; 2000), Crosby (1972; 1986), Dean (1995). 
García afirma que "el conjunto de problemas que suelen agruparse bajo la expresión 'crisis ecológica' es ya una de las encrucijadas abiertas ante la humanidad contemporánea” (García, 2011, p. 16), porque la problemática ambiental presenta en sus raíces un carácter social; y emerge debido a los vínculos que las sociedades establecen con su hábitat en el proceso productivo, tecnológico, cultural y reproductivo. Frente a este panorama, se reconoce la necesidad de establecer un diálogo con otras disciplinas que permitan vislumbrar la complejidad de los procesos estudiados.

La mirada historiográfica tradicional consideró a la naturaleza como un ente estático (existente en medio de procesos sociales variables), mientras que la historia ambiental rehabilita al ambiente como agente histórico activo. Debido a que la principal premisa redunda en comprender que las sociedades no pueden desarrollarse sin atender a los vínculos quecomparten con el mundo natural, el ambiente como objeto de estudio "responde a conceptos y métodos que [...] atraviesan las fronteras entre disciplinas [y por ello requiere] diversas perspectivas de investigación" (García, 2011, p. 17).

En esta línea se inscribe este artículo,donde se tenderán lazos entre diferentes campos de estudio que brinden un planteamiento holístico sobre la problemática ambiental en los medios de comunicación, más precisamente, en la prensa gráfica contracultural argentina. Con este fin, a través del análisis de los topoi-que se explicará en las siguientes páginas - estudiaremos la estructura argumentativa que construye la revista Expreso Imaginario como un "hecho histórico y social" (Angenot, 2012, p.15), considerando que, en cuanto la naturaleza se encuentra determinada por las relaciones sociales de producción, se convierte en objeto de la historia, en parte de un proceso histórico. Es susceptible de ser intervenida, analizada y explicada, ya que las sociedades constituyen y amoldan el medio ambiente para su confort, al tiempo que lo explotan para su desarrollo y supervivencia.

Ello implica que el mundo natural existe y es modificado y transformado por el accionar humano.En este sentido, tal como señalan González de Molina y Matínez Alier (1993)la mirada que tenemos respecto del mundo es principalmente una construcción social, por lo tanto, la concepción que tenemos de la naturaleza es fundamentalmente una elaboración de nuestra mente y es histórica.

Estas disputas ambientales se proyectan también en el universo discursivo y uno de los vehículos de transmisión de los discursos sociales son los medios de comunicación. La importancia de analizar los medios y sus mensajes radica en que son espacios de disputa de poder. Además, son los responsables de mediar e informar sobre las cuestiones ambientales, de acuerdo con determinados criterios profesionales y narrativos de selección y jerarquización. Ejemplo de ello es la revista Expreso Imaginario que surge dentro de una coyuntura compleja de Argentina, con el ascenso de las Fuerzas Armadas al poder entre 1976 y 1983 y se abre camino en el terrero de la prensa contracultural.

\section{De los medios a los discursos}

Los medios de comunicación desempeñan un papel primordial al ser concebidos como un fenómeno social cuyas formas simbólicas se plasman en contextos culturales e históricos precisos, y se constituyen en soportes de los discursos que circulan en la sociedad. Fairclough y Chouliariki consideran a los medios como instrumentos vitales de disputa de poder, ya que se presentan como "neutrales debido a que constituyen un espacio para el discurso 
público[así, en apariencia] reflejan desinteresadamente los estados de cosas[y se muestran como si] no ocultasen las percepciones ni los argumentos de quienes son noticia" (Fairclough y Chouliariki, 2000, p. 25).

Hablar de discurso implica referirse a una práctica social que no es individual, por el contrario, cobra sentido en la esfera social a través de la interacción de los sujetos sociales.

Fairclough y Wodak sugieren pensar el discurso como una "relación dialéctica" por la cual el suceso discursivo "está moldeado por las situaciones, instituciones y estructuras sociales pero a su vez les da forma" (Fairclough y Wodak, 2000, p. 367).Esto implica interpretar el discurso como práctica social, supone entenderlo como una forma de acción capaz de emplear formas lingüísticas que configuran los modos de comunicación y las representaciones de la realidad y del mundo circundante. Por ello, y dada la coyuntura histórica política y cultural en la que emerge la revista Expreso Imaginario, resulta de radical importancia estudiar los discursos que circularon en la prensa contracultural en Argentina.

En este aspecto,Wodak (2003) considera indespensable pensar el discurso en su enfoque histórico, así mismo integra los conocimientos disponibles sobre las fuentes históricas que incluyen los aspectos sociales, políticos y discursivos.En este sentido, el análisis crítico del discurso ${ }^{4}$ surge como una forma de análisis que reconoce"el papel del lenguaje en la estructuración de las relaciones de poder en la sociedad" (Calsamiglia Blancaflort, 2002, p. 22). A su vez, estudia "el lenguaje como práctica social", al tiempo que contempla "el contexto de uso del lenguaje como crucial" (Calsamiglia Blancaflort, 2002, p. 22). Cabe destacar que todos los discursos son históricos y, por lo tanto, solo pueden entenderse por referencia a su contexto (Wodak, 2001). Consideramos al discurso como una expresión sociocultural resultante de un contexto social determinado por la coyuntura histórica. El enfoque histórico del discurso - propuesto por Wodak en 1990 - asociado al análisis crítico, trabaja con perspectivas diversas, de manera multimetódica y se basa en la diversidad de datos empíricos y de información de fondo, busca integrar fuentes históricas, contexto social, político, cultural en el cual se producen los discursos (Wodak, 2003). El encuadre "se orienta hacia los problemas, no se centra en elementos específicamente linguísticos [y la] recontextualización [es] el proceso más importante para vincular esas variedades discursivas, junto con los temas y los argumentos" (Wodak, 2003, p. 109).

De acuerdo con esto, la revista Expreso Imaginario construye su discurso desde la contracultura y, como se verá, en el anclaje de topoi: temas que refuerzan susesquemas argumentativos sobre los problemas ambientales. Es destacable señalar que el discurso siempre es un objeto históricamente producido e interpretado, por ello se sitúa en un tiempo y espacio determinados que deben ser tenidos en cuenta para su análisis (Wodak, 2003). En este artículo proponemos identificar qué argumentos construye Expreso Imaginario para presentar la cuestión ambiental. Con este objetivo, pondremos en diálogo el concepto de topoi instrumentado por Wodak (2003) con los

4 Los inicios formales del análisis crítico del discurso se ubican en la década del setenta con las contribuciones al campo de Gunther Kress y Robert Hodge (1979), Teun Van Dijk (1985), Norman Faircluogh (1989) y Ruth Wodak (1989) quienes ilustraron los principios y procedimientos fundamentales hasta el momento abordados por la lingüística crítica. No obstante, no es hasta a comienzos de la década del noventaque se institucionaliza cuando Wodak, Fairclough, Kress y Van Dijk comienzan a intercambiar, discutir, tanto teorías como métodos. Sin lugar a dudas, la aparición de la revista dirigida por Van Dijk (Discourse and Society) ese mismo año fue una visagra para la consolidación de esta perspectiva. 
criterios propuestos desde la historia ambiental para entender el enfoque mediático que realiza el medio sobre la crisis ambiental, entendiéndola en clave histórica.

\section{El papel de los medios de comunicación en la cultura ambiental}

Los medios de comunicación masiva desempeñan una función central en la configuración de la sociedad moderna. Se constituyen como mediadores necesarios del acontecer social entre el "suceso" y los individuos. Así mismo, son vehículos de transmisión tanto de información como de opiniones, y son responsables de la construcción social de la realidad circundante. Por ello los medios no son neutrales, por el contrario, construyen representaciones sociales particulares que permiten elaborar una determinada concepción del mundo a través de la selección que realizan sobre qué se muestra, qué se omite y qué actores sociales e instituciones se presentan. Establecen agenda gracias, entre otras razones, a la autoridad relativa que la comunidad les ha otorgado (Raiter, 2008) y producen discursos con características y estructuras particulares.

En general, los medios de comunicación han construido sus discursos sobre las problemáticas ambientales partiendo de crisis locales o regionales seleccionando y jerarquizando aquellas que, según su criterio periodístico, son más pertinentes. De esta manera, se propicia la espectacularización ${ }^{5}$ del suceso noticiable en detrimento del análisis y concientización, provocando en la audiencia estados de estupor o perplejidad frente a los hechos narrados.

En este contexto, el estudio de los medios de comunicación es de capital importancia puesto que a través de ellos la sociedad adquiere información y construye, además, su "cultura ambiental". Así, se entiende que los medios son espacios donde se disputan y construyen significados. En ese marco el ambiente ha sido no solo un lugar sino también el campo de batalla donde han contendido ferozmente ideologías y culturas.

Por consiguiente, si tenemos en cuenta que "en la mayoría de los casos los ciudadanos no tienen una experiencia directa con estas problemáticas ambientales" (Lema Blanco y García Mira, 2009, p. 275), los medios de comunicación se tornan indispensables. Siguiendo a Lema Blanco y García Mira (2009) las actitudes ambientales de las personas no pueden entenderse sin comprender el grado de información ambiental al que están expuestas. Por lo tanto, los medios de comunicación brindan la materia prima informativa para la construcción social de las representaciones del ambiente (Bonnes, Nonaiuto, Metastasio, Aiello y Sensales, 1997). Al mismo tiempo, connotan y otorgan significados particulares a aquellos acontecimientos vinculados a problemas ambientales, puesto que actúan como intermediarios entre la realidad de la que informan e interpretan y la sociedad a la que se dirigen (Montero, 2002; Lema Blanco y Meira Cartea, 2007).

En el caso de Argentina, la presencia del tema en los medios de comunicación, en la década del setenta, resulta escasa aunque contundente para el caso de los medios contraculturales. En la revista Expreso Imaginario se mani-

5 Siguiendo a Josefa Bru el concepto de "espectacularización" alude, en primer lugar, ala "utilización de imágenes del medio y de la naturaleza como objetos de consumo visual con alto contenido simbólico"; y, en segundo lugar, al hecho de que "los conceptos, imágenes y valores que las sociedades contemporáneas asignan al medio y a la naturaleza tienen -al contrario de lo que se cree- muy poco que ver con un mayor conocimiento y una experiencia más directa de la realidad de ambos. En cambio, están 'construidos'” (Bru, 1997, p. 169). 
fiesta que, tanto lo que se conoce como lo que se ignora sobre esta problemática no depende de la cantidad de información a la cual se tenga acceso, ya que este razonamiento resulta limitado tanto para la publicación como para el movimiento contracultural al que pertenece. Esto obliga a reflexionar sobre el lugar que ocupa la temática ambiental dentro de la revista: ¿es un tema relevante por tratarse de un acontecimiento que quiebra con la cotidianidad y se torna noticioso? ¿O, en realidad, se trata de un proceso que es clave y propio del clima de época? ¿Hasta qué punto la noticia se vuelve espectáculo y la crisis ambiental un producto redituable para los medios?

Entendemos que la percepción social sobre la problemática ambiental atraviesa tres etapas diferenciadas: la preocupación por el perjuicio hacia la naturaleza; la puesta en acto en búsqueda de soluciones posibles para sanear el problema; y la significación, es decir, la imbricación de la problemática con otros valores culturales. En tanto avanzamos con el estudio de estas fases, el análisis se tornará más complejo; al mismo tiempo, ello señala la especificidad del objeto.

Para Manzini (2000) la mención de cuestiones ambientales en la prensa es relativa y se percibe de acuerdo a factores aleatorios, eventuales y al lugar que ocupa la problemática en los medios. No obstante, aunque no se le otorgue la importancia que reviste y quiera ser opacada con otros temas que, a simple vista, sean más rentables para los grupos económicos y políticos, la crisis ambiental avanza.

\section{Historia y características de Expreso Imaginario}

Expreso Imaginario comienza su circulación en 1976, seis meses después de la usurpación del poder por las Fuerzas Armadas. La publicación dejó de editarse en 1983, cuando el autodenominado Proceso de Reorganización Nacional, ya en decadencia, se retiró de la escena nacional. El cierre de este medio se debió a la partida de dos de sus fundadores, Jorge Pistocchi, en 1980, y Pipo Lernoud, en 1981. En ese momento, la revista quedó bajo la dirección de Roberto Pettinato y se convirtió con exclusividad en una revista dedicada a la música rock. Esto implicó la consecuente pérdida de interés por aquellos temas alternativos que le dieron origen.

Esta revista fue protagonista del mundo contracultural ${ }^{6}$ en la década de los setenta, su existencia se explica como una bocanada de oxigeno necesaria para un sector de la sociedad que, no solo sentía que sus inquietudes

6 Los orígenes de la contracultura se remontan a una coyuntura en constante tensión y enfrentamiento contra el régimen cultural imperante de la convulsionada década de los sesenta. De acuerdo a la conceptualización de Milton Yinger (1960), entendemos la contracultura como "aquellas subculturas en donde los valores se encuentran en oposición al sistema axiológico dominante" (García Naharro, 2012, p. 304). En consecuencia, los movimientos contraculturales se caracterizan, tal como menciona Ken Goffman (2005), por "afirmar el poder del individuo para crear su propia vida más que para aceptar los dictados de las convenciones y autoridades sociales que los rodean" (García Naharro, 2012, p. 304).

El concepto de contracultura se consolidó con un propio estatuto y sistema de valores que reniega la cultura dominante. Estos rasgos se encuentran presentes y atraviesan las páginas de Expreso Imaginario al impulsar -como se verá- una transformación sustancial en los modos de vida de la sociedad. Por su parte, Theodore Roszak definió a los movimientos contraculturales como "una cultura radicalmente [...] desafiliada o desafectada a los principios y valores fundamentales de nuestra sociedad [...] que pretenden transformar el más mínimo sentido de nosotros mismos, los otros y todo lo que nos rodea" (Roszak, 1984, pp. 57-64). Esa es, en esencia, la meta de Expreso Imaginario, no ser solo un órgano de difusión sobre 
no se plasmaban en los medios controlados directa o indirectamente por el Estado Terrorista sino que, al mismo tiempo, padecían en silencio la represión del régimen. Expreso Imaginario es un referente dentro de un universo de revistas que mantuvieron espacios críticos cuando el solo hecho de hablar desde la diferencia implicaba enormes riesgos (Benedetti y Graziano, 2007). Al decir el propio Pistocchi:

$\mathrm{Si}$ al leer el Expreso y pensar en el horror de la época en que fue editado es inevitable imaginar que vivíamos en un mundo aparte, tengo que confesar que así fue [...] Pero no era un mundo que se inventó para ese momento sino que ya existía. Estaba ahí por la valentía de los artistas [...] lo único que nosotros hicimos fue poner en contacto aspectos generados dentro de esa cultura alternativa o marginal (Suplemento Radar, 2002).

A través de sus páginas se consolidó como una publicación pionera en Argentina puesto que, entre otros motivos, permitió la construcción de un espacio de debate y reflexión en torno a un repertorio de temas no convencionales para los medios de comunicación de la época.

Había que explorar otros terrenos. Yo quería hablar de los problemas ambientales, de la poesía aborigen, de cómo llevar adelante una alimentación sana, de filosofías basadas en la paz. ¿Cómo habitamos este mundo sin destrozarlo ni aniquilarnos nosotros mismos? Veía que tanto el capitalismo como el marxismo estaban basados en un sistema energético que nos llevaba irreversiblemente a la muerte, y eso nadie se lo cuestionaba (Diario Página/12, 2015).

La heterogeneidad de contenidos incluía el tratamiento de problemáticas ambientalistas, formas de vida alternativas, divulgación científica, orientalismo, poesía, debates sobre el cine under e información sobre rock.

La singularidad que la caracteriza es fruto, en gran medida, del ingenio, interés y atrevimiento de Jorge Pistocchi, quien fuera columnista de la revista Pelo y luego director de Mordisco ${ }^{8}$. Pistocchi creía necesario el desarrollo de un periodismo alternativo que no solo se interesara por la música rock, sino que pudiera explorar otras disyuntivas:

Creo que el motor fue siempre el mismo: generar un espacio de pensamiento independiente, de acción comunitaria, de experimentación [...] Los temas siguen siendo profundamente los mismos, los que tratan sobre el futuro de la vida en este planeta. Desde que empezamos a salir hasta hoy, yo creo que se ha destruido por lo menos el 50 por ciento de nuestro hábitat [...] Ningún discurso se sostiene si no se revisa un cambio profundo en el uso de las energías [...] Si fantaseamos con sostener la vida en este planeta, toda nuestra energía tiene que estar puesta en ese cambio. Hoy la libertad sigue estando tan comprometida como hace cuarenta años (Diario Página/12, 2015).

la problemática ambiental, sino un vehículo de comunicación y una herramienta para la transformación. Como menciona Fernando García Naharro, la contracultura se comprende como aquello que se opone a lo convencional y "el rechazo frontal a lo instituido, la búsqueda del colapso normativo y la superación de las corrupciones de la cultura dominante constituyen la base de su proyecto" (García Naharro, 2012, p. 304), como veremos en este trabajo, Expreso Imaginario se erige y construye su discurso como ejemplo de este movimiento.

7 Única publicación dedicada a la música pop y al fenómeno hippie, dirigida y creada por Daniel Ripoll.

8 Una revista ligada solo a la música rock que aparece en las calles porteñas en mayo de 1974 y que acompañará en este viaje al Expreso. 
En palabras de Pujol "el hombre era el proyecto de la contracultura hecho realidad" (Pujol, 2011, p.31). La otra cara visible que permitió la aparición de Expreso Imaginario fue Pipo Lernoud, un poeta y compositor de música rock, quien también escribía en las revistas de Ripoll, como Pelo y Algún Día. Ambos concebían fascinados la idea de editarlo que por aquel entonces decidieron que se llamaría Expreso Imaginario. Sin embargo no contaban con el capital necesario para realizar este emprendimiento. Así entra en escena la última pieza de este rompecabezas, Alberto Ohanian, abogado y amigo de Luis Alberto Spinetta ${ }^{9}$, que se erige como financista de la revista. Con él se completaba el trinomio que encabezaría el proyecto, que contó con un staff fijo integrado por Horacio Fontova, Pelusa Confalonieri, Edy Rodriguez, Alfredo Rosso, Claudio Kleiman y Fernando Basabru.

Esta publicación se caracterizó por establecer una agenda propia en la cual se abordaban temas que para un sector de la sociedad -la juventud del momento- revestían de gran interés, aunque eran ignorados en las primeras planas de los medios de comunicación de la época. La revista fue un proyecto que tenía al rock como excusa y vehículo para hablar de otros temas, entre ellos las cuestiones ambientales.

De esta manera, esta clase de publicaciones logró camuflarse a pesar del "espiral de violencia" que enturbia la vida cultural (Pujol, 2007, p. 320). Expreso Imaginario sobrevivió en un período convulsivo para la historia argentina, en la cual los medios que procuraban plasmar una arista diferente de la realidad eran clausurados o censurados. Al decir del propio Pistocchi, "era importante sacar la revista porque veía que estaban a punto de cortarse por completo los canales de comunicación" (Diario Página/12, 2015).

En lo que refiere a la problemática ambiental, se señalan y cuestionan las consecuencias que trae aparejado el incorrecto accionar del hombre, producto del elevado nivel de industrializacón y crecimiento económico de los países desarrollados (García, 2009).

En concordancia, los directores de la revista expresaban que:

Nada detine a los hombres en su carrera aunque por ella sus sentidos se atrofien a fuerza de depender de aparatos que a su vez envenenan su planeta [Expreso Imaginario] solo intenta recorrer su viaje por los espacios no anquilosados de la mente [aquellos que] todavía conserven la frescura suficiente para contener sentimientos de vida (Expreso Imaginario, 1976).

Desde su inicio se advierte que la publicación no se presenta como un órgano de difusión sino como un vehículo de comunicación que se propuso hablar de ecología cuando el tema "solo emergía en los medios de difusión aisladamente, perdido entre noticias aparentemente más urgentes” (Expreso Imaginario, 1978). No obstante, entienden que las épocas cambiaron y “las catástrofes son cada día más evidentes”. Ahora bien, también se aclara que "el problema ecológico [no pasa solo] por las primeras planas de los grandes matutinos [sino que] hay una descomposición progresiva y constante del medio en que vivimos que no llega al conocimiento del público" (Expreso Imaginario, 1978).

Además, enuncia las consecuencias que trae aparejada la crisis ambiental, así como las posibles soluciones que los actores responsables - sea desde la esfera política a nivel gubernamental o bien desde el plano de la ciudadanía- pueden desarrollar para revertir la situación. Como plantea Zabiuk:

9 Cantante, guitarrista, poeta, escritor y compositor argentino de rock, considerado uno de los más importantes y respetados músicos en Hispanoamérica. Es reconocido uno de los padres del rock argentino. Fue líder de los grupos Almendra, Pescado Rabioso, Invisible, entre otros. 
En el caso de los responsables y colaboradores del Expreso, [se buscaba] la difusión de prácticas que cambiaran en un sentido global la vida humana, con la seguridad que la toma de conciencia de los problemas en el mundo, en el que el poder estaba desigualmente distribuido, permitirían construir un futuro diferente (Zabiuk, 2007, p. 45).

Esto invita a pensar en Expreso Imaginario como protagonista y partícipe necesario de lo que Grinberg definió como: "revolución cultural". Entendiendo esto último como aquella necesidad de tomar el poder, no político sino como poder creativo, "con [una evidente] determinación visionaria [unida a un] compromiso profético" (Grinber, 2004, p. 11). En tanto medio de comunicación, transmite una concepción del mundo y se constituyó en un "espacio cultural abierto en una época de censura y autocensura en la mayoría de los medios de comunicación” (Zabiuk, 2007, p. 44). De este modo, Expreso Imaginario se consolidó como un reducto contracultural, innovador y vanguardista.

\section{Las estrategias argumentativas en torno a los problemas ambientales. Un posible abordaje metodológico}

La percepción y el grado de receptividad de la población de los problemas y riesgos ambientales para García Mira y García González (2007) se relacionan con la forma en que estos son presentados por los medios ante la opinión pública. Por esta razón, es importante tanto la visualización de las catástrofes como el debate y el abordaje teórico transdisciplinar sobre la problemática, a fin de aproximar a la sociedad la complejidad del caso (Lema Blanco y García Mira, 2009).Conforme a lo expresado, entendemos que el hombre plantea una relación con la naturaleza a lo largo de la historia, a la vez que adquiere determinadas características psíquicas, físicas y sociales, de acuerdo con el medio que lo rodea y la ideología dominante. Esto implica la construcción de metáforas y representaciones que conforman discursos.

En el presente artículo, tomaremos tres notas ${ }^{10}$ de la revista Expreso Imaginario, correspondientes a los años 1976-1978, donde se evidencia un mayor caudal de información relativa a la problemática ambiental y que además consideramos resultan altamente representativas al momento de evidenciar el abordaje que el medio realiza

10 Coherente con la liturgia propia de la contracultura, la revista Expreso Imaginario no persigue las clasificaciones periodísticas tradicionales con las que podemos identificar en la actualidad los géneros periodísticos. Por el contrario, no se presentan secciones fijas y establecidas, el eclectisismo de su temática se traduce también a su formato y presentación. En este sentido, resulta anacrónico establecer una clasificación con categorías del presente para analizar la información brindada por la publicación. Por ello, para este trabajo, procuraremos estudiar el contenido de Expreso Imaginario englobado bajo la estructura de "notas". Estas narran "un hecho o una situación mediante técnicas de redacción que permiten mayor libertad en el modo de transmitir la información [y que, a su vez] admiten un estilo personal y recursos expresivos propios de la literatura" (Morosi, 2013, p.29). Por su parte, las notas "poseen una estructura fija con un copete que puede alcanzar el primer y segundo párrafos; el cuerpo o desarrollo (si son textos extensos suelen incorporar subtítulos); y un remate en el último párrafo" (Morosi, 2013, p. 29). Además, cuenta con una flexibilidad que permite "copetes informativos como los de una noticia o crónica, descriptivos del escenario donde transcurrió la acción a narrar, declarativos a partir de citas textuales entrecomilladas y de impacto que pueden incluir preguntas o exclamaciones" (Morosi, 2013, p. 29). 
sobre la temática de análisis: "Ecología: la vida pierde la batalla" (1976), "Crash! Y si se rompe el equilibrio ecológico?” (1977), “La ecología ese difícil equilibrio de la vida”(1978). Desde la mirada de la historia ambiental, estos ejemplos permiten vislumbrar cómo la intervención humana configura y modifica la naturaleza ( $0^{\prime}$ Connor, 2001) ya que, como veremos, hacen hincapié en la forma en que hombre y ambiente se relacionan,el modo en que el hombre es afectado por el ambiente natural y, al mismo tiempo, de qué manera el género humano perjudica a la naturaleza.

A partir de la lectura y consiguiente análisis de las notas mencionadas, identificamos siete topoi cuyos argumentos se relacionan con la cuestión ambiental y atraviesan toda la publicación, a saber: equilibrio, vida, natural, salud, sustentabilidad, recursos naturales, contaminación. Este trabajo se sitúa en la intersección de dos enfoques teóricos: por un lado, el análisis crítico del discurso que considera el uso del lenguaje en un contexto histórico y social, donde discurso y sociedad se encuentran en una relación dialéctica; así, el discurso es constitutivo de la sociedad y a la vez es constituido por ella (Fairclough y Wodak, 2000; Fairclough, 2008). Por otro, la historia ambiental que comprende la relación dialógica entre la esfera natural y social; además, atiende a cómo los modos de producción y organización social repercuten directamente en ese vínculo.

Desde la teoría de la argumentación de Wodak (2003), los topoi son elementos de la argumentación que

Forman parte de las premisas obligatorias [tengan] carácter explícito o precisen de inferencia. Son justi-

ficaciones relacionadas con el contenido, también conocidas como "reglas de conclusión", que vinculan

el argumento o los argumentos con la conclusión, esto es, con [la idea] que se pretende afirmar (Wodak,

2003, p. 115).

Wodak (2003) distingue cinco herramientas dentro de su teoría de la argumentación, a saber:

Referencia o modo de nombrar: esta categoría de análisis se pregunta "¿de qué modo se nombra a las personas y de qué modo se hace referencia a ellas?".

Predicación: es el "etiquetado de los actores sociales de forma más o menos positiva o negativa, más o menos desaprobadora o apreciativa”. La pregunta que se plantea es "¿qué rasgos, características, cualidades y particularidades se les atribuyen?".

Argumentación: justificar las atribuciones negativas o positivas mediante las cuales se ha etiquetado a los actores sociales. La pregunta que se plantea es por medio de qué argumentos y esquemas argumentativos se trata de legitimar la exclusión, la discriminación, la supresión y la explotación de los otros.

Perspectiva: El interrogante reside en averiguar desde qué perspectiva o punto de vista se expresan las etiquetas, atribuciones y argumentos, con el objetivo de ubicar el punto de vista del que habla.

Intensificación/Atenuación: con el objetivo de modificar la posición epistémica de una preposición, la pregunta es si se articulan abiertamente las respectivas afirmaciones, y si resultan intensificadas o atenuadas, en relación a la fuerza ilocucionaria de las afirmaciones (Wodak, 2003, pp. 114-116).

Si bien Wodak ha desarrollado esta teoría pensando en términos de exclusión, discriminación, supresión y explotación, siguiendo a la autora es posible plantear interrogantes que se ajusten a la presente investigación, a saber: ¿bajo qué argumentos y estructura argumentativa se presenta y emerge la problemática ambientalista en la revista Expreso Imaginario y cómo ello dialoga con la historia ambiental? ¿El tratamiento mediático sobre las cuestiones ambientales en la revista apunta a la espectacularización de la situación o se opone a esa visión? 
A fin de poder esbozar una respuesta a estos interrogantes, a modo de ejemplo, fueron seleccionados - del total de topoi identificados- los de equilibrio y vida. Por un lado, estos topoi se configuran como los más representativos y aquellos que el medio refiere como ejes de tensión a lo largo de su publicación y, por el otro, porque permiten vislumbrar los argumentos que la revista presentó para mencionar la problemática ambiental en el periodo de estudio.

\section{Elementos de la argumentación en Expreso Imaginario}

A continuación ponderamos los fragmentos más representativos de las notas seleccionadas de Expreso Imaginario en donde se manifiesta el topos de equilibrio (entre 1976 y 1978). Se evidencia con claridad cómo, paulatinamente, la revista construye su postura sobre la cuestión ambiental. A fin de otorgar mayor claridad se decidió resaltar los modos en que se hace referencia alas acciones que, como enunciador, realizala revista en su construcción discursivaal referirse a la temática ambiental.

1. Los científicos sostienen que fue gravemente alterado el equilibrio ecológico en la biosfera o zona de vida del mundo, y se distorsionó el llamado reciclaje.

2. Los herbicidas y defoliantes utilizados militarmente por Estados Unidos en Vietnam, destruyeron el $45 \%$ de los árboles, alterando la ecología de la península indochina.

3. Cuando el hombre rompe ese equilibrio [...] la rápida propagación de animales y plantas pone en peligro toda la armonía biológica existente.

4. Hay especies animales y vegetales ya extinguidas, hay otras que, de a poco, van desapareciendo ante un medio hostil, porque se mata por matar, se explota sin control, se abusa suicidamente para satisfacer las necesidades frívolas de nuestra civilización.

5. Cosas tan comunes en esta época como la contaminación, la utilización indiscriminada de los recursos naturales, la irreversible desaparición de especies animales, no son más que factores que nos dirigen progresivamente al ecodesastre.

6. Un ecositema puede ser perturbado hasta un cierto límite a partir del cual su poder autoregulador reestablece el equilibrio. Si este poder no logra reestablecer su equilibrio, el ecosistema desaparece.

Las atribuciones que se identifican en la relación hombre-ambiente son construidas discursivamente en Expreso Imaginario por medio de valoraciones negativas. Los rasgos que se desprenden de estas enunciaciones son desaprobadores y negativos. Ello se puede advertir mediante la utilización de verbos como: alterar, romper, explotar, etc. Así, se observa cómo, discursivamente, el vínculo sociedad-naturaleza se construye a través de las acciones negativas que modifican el estado natural del medioambiente. Se genera una permanente tensión entre las acciones del hombre sobre la naturaleza que, a su vez, atentan contra el futuro de las sociedades, como se mostrará a continuación con los siguientes ejemplos. En este sentido, la contextualización de la naturaleza se presenta aquí como resultado de un proceso de interacción históricamente construido en constante diálogo con las sociedades.

En el siguiente caso identificamos los fragmentos más representativos de las notas seleccionadas de Expreso Imaginario en donde se manifiesta el topos de vida (entre 1976 y 1978). Se resaltanlas referencias que figuran con 
respecto a las acciones que, como enunciador, realiza la revista en su construcción discursiva al referirse a la temática ambiental.

1. Los científicos han llegado a conclusiones sobrecogedoras acerca del flagelo que se desplaza por aire, tierra y mar.

2. Los estudiosos del tema incluso hablan de "suicidio inconsciente" .

3. Niños, mujeres, hombres, seres aún sin nombre que madres jovenes cultivaban en sus vientres, animales, pájaros, peces, mariposas, gusanos, raices, flores, cayeron arrasados por la nube gaseosa [de dioxina]. Ninguna indemnización [por la liberación de veneno de una fábrica de cosméticos] los hará resucitar.

4. [En la tierra] vivimos, respiramos, comemos, nos movemos, aquí conviven con nosotros todas las especies animales y vegetales. Es nuestra gran casa, hoy peligra su calma, su belleza, su vida y la nuestra. La acción del hombre sobre ella es como un lento suicidio, su destrucción no nos lleva más que a nuestra propia muerte.

5. La naturaleza es aparentemente infinita pero tiene un término para las condiciones en que podemos vivir. Estas condiciones desaparecerán mucho antes de lo que suponemos, todos nosotros tenemos que tomar conciencia de esta amenaza que pende sobre todas nuestras cabezas.

6. Dijimos que en muchos aspectos es demasiado tarde pero también nos queda una oportunidad de decidir y elegir entre la vida y la desaparición y muerte.

Las construcciones que Expreso Imaginario elabora sobre la relación hombre-ambiente derivan, indefectiblemente, en crisis ambiental. Una vez más, discursivamente, desde la revista, el hombre actúa sobre su entorno en forma negativa ya que: altera, distorsiona, rompe, explota. Al tiempo que también hace desaparecer, aniquila, perturba, flagela, envenena, arrasa, destruye y amenaza a la naturaleza. Es decir que, la construcción discursiva de Expreso Imaginario habla sobre la facultad que tiene el hombre para realizar acciones e intervenir sobre el entorno natural, apropiándose y dilapidando sus recursos.

Siguiendo la línea propuesta por Wodak (2003), en términos de predicación el etiquetado de los actores sociales, en este caso de los seres humanos, hace foco en las características y rasgos desfavorables, dañinos, destructivos y perniciosos que se traducen en su vínculo con la naturaleza. Al mismo tiempo, las justificaciones de esas atribuciones negativas que el medio realiza nos permiten argüir los esquemas argumentativos que elabora Expreso Imaginario y que responden a los topoi:

1. Equilibrio/Desequilibrio: Si la intervención del hombre impacta negativamente sobre el ambiente, entonces se deben modificar/repensar sus prácticas.

2. Vida/Muerte: Si los modos de producción ponen en peligro y amenazan la vida, se deberán replantear las formas de organización social.

La perspectiva desde la cual esta publicación establece estas estructuras argumentativas se construye a partir del hincapié que hace la revista respecto de los modos en que las sociedades se vinculan con la naturaleza, destacando el obrar negativo del hombre sobre el entorno. A su vez, el medio intensifica su postura con el transcurrir del tiempo, evidenciando en su discurso abiertamente su posición al respecto.

Una lectura en clave histórica de este problema nos permite entender que, cada grupo social construyó una manera particular de interactuar con el medioambiente, de acuerdo a su cultura y tecnología. Conforme las condiciones materiales de la sociedad cambian, esa relación con la naturaleza también difiere, puesto que las variacio- 
nes en la naturaleza acontecen con temporalidades diferentes a las de la sociedad. Como consecuencia de ello, la relación naturaleza-sociedad se complejiza.

Como menciona Santamarina Campos, el medio ambiente se comporta como un referente que abre las posibilidades de reflexionar sobre nuestro mundo. Al mismo tiempo, por su fisonomía polifacética, es capaz de encapsular y simbolizar un déficit en aspectos internos de nuestra práctica cultural (Santamarina Campos, 2006, p.14).

En los ejemplos escogidos se evidencia que, en tanto la naturaleza se encuentra determinada por las relaciones sociales de producción, se convierte en objeto de la historia. Así, resulta indiscutible que el devenir histórico no se limita solo a lo humano. De igual modo, el ambiente no se acota únicamente a lo biológico. Por el contrario, y como se plantea desde la historia ambiental, el ambiente es definido por los procesos políticos, sociales y económicos que protagonizan los hombres y las sociedades en su apropiación de los espacios y en la utilización de sus recursos.

En este sentido, como se explicitó con anterioridad, si el hombre - por medio de su accionar- condiciona negativamente al ambiente, genera un inminente desequilibrio en el mundo natural. Esto afecta no solo a las especies animales y vegetales sino que, además, conduce a la muerte de la propia especie humana debido a que, frente al accionar depredador del hombre, el ambiente no se regenera de manera infinita. No obstante, el fin último de toda sociedad ha sido la satisfacción de sus necesidades materiales y para ello requirió siempre usufructuar los recursos de la naturaleza, modificándolos según sus necesidades productivas.

En este sentido, los problemas ambientales persisten ya que para revertir la situación se requiere una transformación de aquellas técnicas de producción y consumo, lo que conlleva a reflexionar sobre nuestra propia organización y práctica social.

La estrategia discursiva de Expreso Imaginario, es propia del espacio que ocupa la publicación en el espectro contracultural argentino. Si es posible entender la contracultura como un movimiento que promueve un cambio de estado de las cosas existentes, entonces, la identificación de la problemática ambientalista en la revista es factible considerarla como un argumento insoslayable. Además, construye un discurso donde se focaliza en la necesidad de comprender los tiempos que requiere la naturaleza para generar recursos, dado que los ciclos naturales son más extensos y complejos que aquellos de las sociedades.

De esta manera, los topoi que recorren la publicación refieren a las intervenciones del hombre sobre el ambiente, las cuales resultan invasivas y violentas al tiempo que alteran los ciclos naturales de los ecosistemas. Ello implica que los tiempos de reproducción de recursos naturales no son compatibles con los de su explotación "artificial".

Si consideramos que la naturaleza es un agente activo e histórico en constante diálogo con la sociedad y es a través de esa forma de relacionarse la que otorga sentido a los vínculos que establecemos entre nosotros y el mundo, el ambiente deja de percibirse como algo externo al hombre y comienza a pensarse como propio. El hombre se coloca como generador del problema y protagonista indiscutible para elaborar una solución que oficie otro modo de existir en el planeta Tierra y de vincularse con la naturaleza.

Bajo este contexto, Expreso Imaginario alza la voz por el ambiente, por los temas no convencionales y no abordados por los grandes medios de comunicación. Alerta sobre la problemática ambiental y demanda una reacción y la concreción de un programa de cambios - un elemento propio de la contracultura- que atienda a la premisa de que otra realidad es posible; y así, lo manifiesta en los topoi presentes en su discurso. 


\section{Consideraciones finales}

Construir desde la resistencia es la clave de Expreso Imaginario, donde su discurso está signado por el afán de concretar una transformación cultural y de impacto social. La revista interpela a sus lectores con un proyecto que excede la agenda ordinaria establecida por los medios de comunicación dominantes de la época al tiempo quese posiciona como promotora de la contracultura en Argentina. Así mismo, gracias a su autarquía periodística e informativa, estableció qué temas eran relevantes y cuáles carecían de importancia, se instaló en el mundo de la prensa gráfica contracultural como pionera en Argentina por tratar temas que ningún otro medio se atrevía siquiera a considerar, como el orientalismo, la divulgación científica, el ambientalismo, marcando una agenda propia. La propuesta de Jorge Pistocchi y Pipo Lernoud, lejos de poder etiquetarla como corriente u ordinaria, tuvo la habilidad para sobrevivir y permanecer en circulación en tiempos virulentos. Dada su singularidad y su manera de abordar los temas, logró sortear las barreras de la censura y la persecución dado que para los censores, cuanto mucho, se trataba de una revista incongruente.

El presente artículo no agota el estudio sobre la publicación, sin embargo, el análisis articulado sí privilegia el entendimiento y la cabal comprensión tanto de la práctica discursiva como de la práctica social. Las herramientas implementadas para el análisis permitieron, mediante la identificación de topoi y esquemas argumentativos, entender cómo emerge la problemática ambientalista en Expreso Imaginario - en la década de los setenta- y dialoga con la historia ambiental, no en términos de espectacularización sino como una preocupación fidedigna.

Resulta significativo su abordaje puesto que, en tanto vehículo de comunicación con la sociedad, es un medio que participa en la construcción de representaciones del mundo, de la cultura y de las relaciones que se generan en la sociedad. En cuanto a las cuestiones ambientales, la propuesta era manifiesta: la preocupación por el deterioro y la crisis ambiental es evidente y recorre, durante los tres primeros años, toda la publicación. Por consiguiente, se coloca como portavoz de los inicios del ambientalismo en Argentina.

No obstante, creemos necesario destacar que su propuesta no involucra una presentación "espectacularizada" sobre los problemas ambientales del momento. No utiliza la información sobre las catástrofes y riesgos ambientales como objetos de consumo mediático sino, por el contrario, se hace eco del alto contenido simbólico y real de sus demandas.

En un tiempo donde las catástrofes concentran la mirada mediática, tanto por su gravedad como por su excepcionalidad, Expreso Imaginario construye su discursividad desde un pensamiento movilizador no tóxico. Bernardo y Pellisser sugieren que "cuanto mayor es la incertidumbre, mayores son las consecuencias y mayores las dificultades para trasladar los hechos al espacio y el tiempo de los medios" (Bernardo y Pellisser, 2010, p. 108), pues bien en esta publicación se aboga justamente por dar certezas y no incertidumbres.

La revista ponderó la crítica sobre los modos en que el hombre se vincula con el entorno natural. Para ello intensificó sus argumentos utilizando como instrumento primordial los topoi equilibrio/desequilibrio y vida/ muerte. Gracias a estas estructuras logró construir sus argumentos sobre las causas de la crisis ambiental y sus consecuencias futuras.

Debido a que la problemática ambiental presenta en sus raíces un carácter social, entendemos que las ciencias sociales deben cumplir un rol primordial en el momento de analizar y entender la relación entre hombre-me- 
dio. Así mismo, puesto que las variables de este problema son también económicas, productivas y culturales, consideramos que la solución no debe abordarse solo desde el ámbito de las ciencias biológicas sino que debe ser también una resolución política. No solo en aquella época sino también considerando las problemáticas ambientales vigentes en la actualidad, tanto a nivel local, regional como mundial.

Frente a este contexto, se reconoce la necesidad de establecer un diálogo con otras disciplinas que permitan vislumbrar la complejidad de los procesos estudiados. Por este motivo, la historia ambiental plantea un desafío al establecer un puente que vincula la historia con las ciencias naturales y, por consiguiente, pone en tensión un espacio hegemónico de saber dónde las posturas tradicionales de entender el mundo social y natural entran en conflicto.

Este es un punto central también para leer a Expreso Imaginario en clave contracultural, ya que la tendencia a inclinarse por la temática ambiental consolidó a la revista dentro de este campo. La publicación identifica como causante de la crisis ambiental al hombre, lo ubica como el portador tanto del conflicto como de la solución, y pugna por la armonía entre el hombre y su entorno natural. En este sentido, el análisis del discurso de esta revista también puede aportar a la comprensión de la crisis ambiental actual, dado que presenta las bases del conflicto, reconstruye los orígenes - al menos discursivos - de la problemática y ofrece la información necesaria para poder entender cuáles fueron los motivos que causaron antaño trastornos en la naturaleza. A su vez, esto habilita la reflexión sobre si los modos actuales de relacionarse que tienen las sociedades con el ambiente difieren profusamente de aquellas del pasado.

En este sentido, todas las sociedades construyen una representación respecto al mundo natural e instituyen un vínculo particular con la naturaleza. Así, el concepto de naturaleza varía, por lo tanto, no es algo dado sino que se considera una creación del hombre y se erige como un pilar fundamental en la construcción de las relaciones sociales y de los modos de producción tanto material como simbólica.

Por consiguiente, si bien la naturaleza existe más allá de cómo sea conceptualizada por el hombre, lo que queremos enfatizar es la importancia radical que conlleva considerar estas entidades como una unidad indisociable, como un conjunto complejo y necesario para comprender los conflictos que de ellos se desprenden, en tanto agentes históricos en diálogo.

En este sentido, entendemos que la ausencia - o la mínima presencia- de información sobre la problemática ambiental en los grandes medios de comunicación de la época - década del setenta-dice más de los medios que de la propia problemática de análisis. El modo de encarar y presentar la temática implica advertir la emergencia de la cuestión ambiental -y, por tanto, la relación entre sociedad y ambiente-como tema de época.

A raíz de estas observaciones, se deja abierto un interrogante para continuar discutiendo: ¿es factible pensar lo ambiental en tanto elemento propio de la contracultura? ¿O bien, se trata de una temática noticiable para los medios de comunicación?

Recapitulando, como consecuencia del estudio presentado, cabe cuestionarse entonces si para la década de los setenta la cuestión ambiental puede considerarse una dimensión propia del movimiento contracultural, o bien es un indicador del cambio de época.

A su vez, esto conduce a una reflexión aún más compleja y abierta acerca de qué papel tiene o debería tener tanto la historia ambiental como el análisis crítico del discurso, en tanto metodologías para articular, abordar y entender el discurso ambiental en los medios de comunicación. 


\section{Referencias}

1. Angenot, M. (2012). El discurso social. Los límites históricos de lo pensable y lo decible. Buenos Aires: Siglo XXI.

2. Bechmann, G. (2004). Riesgo sociedad posmoderna. En J. L. Luján y L. Echeverría (Eds.). Gobernar los riesgos. Ciencia y valores en la sociedad del riesgo. Madrid: Biblioteca Nueva, pp.17-33.

3. Benedetti, S. y Graziano, M. (2007). Estación Imposible. Periodismo y contracultura en los setenta: la historia del Expreso Imaginario. Buenos Aires: Marcelo Héctor Oliveri.

4. Bernardo, J. M. y Pellisser, N. (2010). La naturalización mediática de las catástrofes. Una aproximación crítica. En Cuadernos de Información (26), 103-114). Recuperado de http://www.redalyc.org/articulo. oa?id=97114962010

5. Bru, J. (1997). Medio ambiente: poder y espectáculo. Barcelona: Icaria.

6. Calsamiglia Blancaflor, H. y Valls Tusón, A. (2002). Las cosas del decir. Manual de análisis del discurso. Barcelona: Editorial Ariel.

7. Estenssoro Saavedra, F. (2009) La perspectiva histórica para comprender el fracaso de la Cumbre de Cambio Climático en Copenhague. En Justiça do Direito,23, (1), 9-27.

8. Fairclough, N. (1992). Discourse and Social Change. Londres: Polity Press.

9. Fairclough, N. (1995). General Introduction. Critical Discourse Analysis the Critical Study of Language. [Traducción Federico Navarro; recuperado de https://discurso.files.wordpress.com/2009/02/fairclough1995analisis-critico-del-discursocap-1trad-navarro1.pdf

10. Fairclough, N. y Wodak, R. (2000). Análisiscrítico del discurso. En T. Van Dijk (Comp.). El discurso como interacción social. Barcelona: Gedisa.

11. Foster, B. J. (2002). La ecología de Marx. Materialismo y naturaleza. España: El Viejo Topo.

12. Gallini, S. (2009). Historia, ambiente, política: El camino de la historia ambiental en América Latina. En Nómadas, (30), 92-102. Colombia: Universidad Central de Colombia. Recuperado de http://www.redalyc. org/pdf/1051/105112060008.pdf

13. Foucault, M. (1973). El orden del discurso. Buenos Aires: Tusquets Editores.

14. García, E. (2011). Medio ambiente y sociedad: La civilización industrial y los límites del planeta. Madrid: Alianza Ensayo.

15. García Naharro, F. (2012) Cultura, subcultura, contracultura "Movida” y cambio social (1975-1985).En C. Navajas Zubildiay D. Iturriaga Barco(Eds.).Coetánea. Actas del III Congreso Internacional de Historia de Nuestro Tiempo. Logroño: Universidad de La Rioja, pp. 301-310.

16. González de Molina, M. (1993). Historia y medio ambiente. Madrid: Eudeba.

17. Grinberg, M. (2004). La generación "V": La insurrección contracultural de los años sesenta. Buenos Aires: Emecé.

18. Leal, Claudia. (2002). La naturaleza en los estudios sociales. En G. Palacio y A. Ulloa (Eds.), Repensando la naturaleza. Encuentros y desencuentros disciplinarios en torno a lo ambiental. Colombia: Panamericana Formas e Impresos S.A, pp.123-137. 
19. Lema Blanco, I. y García Mira, R. (2009). La sensibilización y formación ambiental de los periodistas que informan sobre medio ambiente. Un enfoque socioeducativo. En Sostenibilidad, valores y cultura ambiental. Madrid: Ediciones Piramide.

20. Manzini, E. y Bigues, J. (2000). Ecología y democracia. De la injusticia ecológica a la democracia ambiental. Barcelona: Icaria.

21. Morosi, P. (2013). Cuadernillo de gráfica. Bernal: Universidad Nacional de Quilmes.

22. O’Connor, J. (2001). ¿Qués es la historia ambiental? ¿Por qué historia ambiental? En Causas naturales. Ensayos de marxismo ecológico. México: Siglo XXI.

23. Palacio, G. (2003). En búsqueda de conceptos para una historiografía ambiental. Simposio de Historia Ambiental Americana. Santiago de Chile.

24. Pujol, S. (2007). Rebeldes y modernos. Una cultura de los jóvenes. En D. James, Violencia, proscripción y autoritarismo: 1955-1976. Buenos Aires: Sudamericana.

25. Pujol, S. (2011). Rock y Dictadura. Crónica de una generación (1976-1983). Buenos Aires: Booket.

26. Raiter, A. (2008). La caja de Pandora. La representación del mundo en los medios. Buenos Aires, La Crujía.

27. Rodríguez, I. (2012). La "nave espacial tierra" de Kenneth Boulding. En Revista de Economía Crítica, (14).

28. Santamarina Campos, B. (2006). Ecología y poder. El discurso medioambiental como mercancía. España: Catarata.

29. Santamarina Campos, B. (2008). Antropología y medio ambiente. Revisión de una tradición y nuevas perspectivas de análisis en la problemática ecológica. En Antropólogos Iberoamericanos en Red, 3 (2).

30. Soluri, J., Pádua, J. A. y Leal, C. (2013). Nuevas historias ambientales de América Latina y el Caribe. Múnich: Rachel Carson Center.

31. Wodak, R. (2003). De qué trata el análisis crítico del discurso (ACD). Resumen de su historia, sus conceptos fundamentales y sus desarrollos. En R. Wodak y M. Meyer, Métodos de análisis crítico del discurso. Barcelona: Gedisa.

32. Wodak, R. (2003). El enfoque histórico del discurso. En R. Wodak y M. Meyer, Métodos de análisis crítico del discurso. Barcelona: Gedisa.

33. Worster, D. ([1984] 2000). Transformaciones de la Tierra. Una antología mínima de Donald Worster. Panamá: Instituto de Estudios Nacionales.

34. Zabiuk, M. G. (2007). Las revistas de rock en la Argentina. En Trampas de la comunicación y la cultura. Rock, cultura y comunicación. Recuperado de http://www.acuedi.org/ddata/9090.pdf

35. Zarrilli, G. A. (2011). Historia ambiental: nuevas miradas y perspectivas en la historiografía argentina. En N. Blacha-Girbaly B. Moreira, Producción de conocimiento y transferencia en las ciencias sociales. Buenos Aires: Imago Mundi Ediciones.

36. Zarrilli, G. A. (2014). Argentina, tierra de promisión. Una interpretación historiográfica de las relaciones entre la historia rural y la historia ambiental. En Revista de Historia Iberoamericana,7 (1), 107-132. 


\section{Artículos periodísticos}

37. Pérez, M. (2002). Qué se puede hacer salvo hacer revistas. Diario Página/12. Recuperado de http://www. pagina12.com.ar/diario/suplementos/radar/9-446-2002-10-27.html

38. Romeral, D. F. (2015). El rock fue una grieta que permitió hacerse preguntas. Diario Página/12. Recuperado de http://www.pagina12.com.ar/diario/suplementos/espectaculos/17-34587-2015-01-29.html ]

\section{Fuente de análisis}

39. Revista Expreso Imaginario (1976-1983). Buenos Aires: Ediciones de la Ventana. 